\title{
Caracterização das notificações de violência contra adolescentes
}

Caracterizar a violência notificada no Rio Grande do Sul contra adolescentes na faixa etária dos 10 aos 19 anos, segundo dados do Centro Estadual de Vigilância em Saúde, no período entre 2009 e 2010. Método: Estudo epidemiológico-descritivo e transversal de dados secundários. Resultados: Foram notificados 337 casos em 2009 e 1559 em 2010, prevalecendo vítimas do sexo feminino. Na faixa etária de 10 a 14 anos, o pai, a mãe e o padrasto foram, respectivamente, os principais perpetradores, enquanto que, entre os 15 e 19 anos foram os parceiros amorosos. Conclusão: Deve-se investir na proteção aos adolescentes e no estímulo à notificação.

Descritores: Adolescente, Violência, Notificação de Abuso.

\section{Characterization of reports of violence against adolescents}

To characterize the violence reported in Rio Grande do Sul against adolescents from 10 to 19 years old, according to the State Center for Health Surveillance in the period between 2009 and 2010. Method: It is an epidemiological and descriptive study and cross-sectional secondary data. Results: 337 cases were reported in 2009 and 1559 in 2010, prevailing female victims. At the age from 10 to 14 years old, the father, mother and stepfather were, respectively, the main perpetrators, while the range from 15 to 19 years old increases the violence originated by loving partners. Conclusion: One should invest in adolescents' protection and to stimulate notification.

Descriptors: Adolescents, Violence, Abuse Reporting.

\section{Caracterización de las denuncias de violencia contra los adolescentes}

Caracterizar la violencia reportada en el Rio Grande do Sul contra adolescentes con edades entre 10 y 19 años, según dados del Centro Estatal de Vigilancia en Salud en el período entre 2009 y 2010. Método: Estudio epidemiológico-descriptivo y transversal de dados secundarios. Resultados: Fueron reportados 337 en 2009 y 1559 en 2010, imponiéndose a las mujeres víctimas. En el grupo de edad de 10 a 14 años el padre, la madre y el padrastro fueron, respectivamente, los principales perpetradores, mientras en el grupo de los 15 a los 19 años aumentan las violencias originadas por las parejas amorosas. Conclusión: Hay que invertir en la protección de los adolescentes y para estimular la notificación.

Descriptores: Adolescente, Violencia, Notificación de Abusos.

\section{INTRODUÇÃO}

$\mathrm{N}$ a contemporaneidade, o fenômeno da violência parece cada vez mais assolar a existência do ser humano, pois alcança progressivamente proporções maiores em todo o mundo, afetando as diferentes culturas, religiões e classes sociais, assumindo um papel de destaque nas estatísticas de morbimortalidade. A violência pode ser compreendida como um fenômeno construído socialmente e influenciado pelas transformações políticas, sociais, educacionais, econômicas e culturais. Compreende-se, contudo, que a violência tem suas raízes na estrutura e no modo de viver de cada sociedade, por isso ganha novas formas e conotações em cada momento da história.(1)

Apesar de atos violentos serem praticados desde os primórdios da humanidade, somente no século XX foram identificados como obstáculo para a saúde das crianças e adolescentes, passando a chamar a atenção da sociedade.(1) Entende-se, portanto, que a violência que acomete essa faixa etária é atravessada por relações de poder, historicamente construídas e que se perpetuam no contexto atual.

A violência foi classificada pela Organização Mundial de Saúde como pertencente ao grupo das causas externas, representando uma das principais causas de morbimortalidade para a população jovem, entre 10 e 29 anos, principalmente nos países em desenvolvimento, onde frequentemente há maiores desigualdades sociais e ausência de políticas públicas voltadas para esse público.(2)

A Organização Mundial da Saúde (OMS) conceitua violência como o uso intencional da força física ou do poder, real ou em 
ameaça, contra si próprio, o outro ou um grupo, que resulte ou possa gerar lesão, morte, dano psicológico, deficiência de desenvolvimento ou privação. ${ }^{(2)}$ Esse fenômeno também tem sido classificado conforme as características de quem comete o ato de violência: violência dirigida a si mesmo (autoinfligida); violência intrafamiliar e violência comunitária (por contatos próximos, interpessoal); ou violência social, política e econômica (por grandes grupos ou pelo Estado, chamada de coletiva).(2)

Quanto à natureza, os atos violentos podem ser divididos em físicos, psicológicos, sexual, privação ou negligência. A violência física é compreendida como toda ação que causa dano físico, pode ser uma lesão leve até o espancamento fatal; violência psicológica, entendida como tortura psicológica, ocorre quando o adulto constantemente deprecia a criança e/ou o adolescente, bloqueia seus esforços de autoaceitação, afetando sua saúde mental; violência sexual é todo ato ou jogo sexual, relação hétero ou homossexual entre um ou mais adultos e uma pessoa menor de 18 anos, tendo por finalidade estimulá-la sexualmente ou utilizá-la para obter uma estimulação sexual. Negligência representa uma omissão em termos de prover as necessidades físicas e emocionais de uma criança ou adolescente, configura-se quando os pais ou responsáveis não atendem aquilo que é indispensável ao adequado crescimento e desenvolvimento, incluindo falta de amor, carinho e responsabilidade. ${ }^{(3,4)}$

No Brasil, os casos de violência passaram a receber maior atenção no final dos anos 1980, quando a Constituição Federal Brasileira - CFB (art. 227) e o Estatuto da Criança e do Adolescente ECA, Lei 8.069/90, (art. 13) tornaram obrigatória a notificação de casos suspeitos e/ou confirmados, prevendo em seu art. 245 penalidades para médicos, professores e responsáveis por estabelecimentos de saúde e educação que deixassem de comunicar os casos suspeitos ou confirmados. Apesar das determinações legais, a subnotificação da violência ainda é uma realidade no Brasil, o que tem sido relacionado à dificuldade de identificar os casos de violência que chegam até os serviços de saúde, pois a imprecisão dos dados limita a sua acurácia. ${ }^{(5)}$

No Estado do Rio Grande do Sul, a Portaria no. 40/2004 da Secretaria Estadual da Saúde - SES/RS - estabelece a obrigatoriedade da notificação compulsória de casos suspeitos ou confirmados de maus-tratos contra crianças e adolescentes atendidos na rede do Sistema Único de Saúde - SUS, através do Relatório Individual de Notificação de Acidentes e Violência - RINAV, disponibilizado pela Secretaria Estadual de Saúde aos municípios. ${ }^{(6)}$

Considerando o exposto, desenvolveu-se um estudo com o objetivo de caracterizar as notificações de violência contra adolescentes, segundo dados do Centro Estadual de Vigilância em Saúde - CEVS - do Rio Grande do Sul no período entre 2009 e 2010. Focaliza-se especificamente nos adolescentes por considerar as particularidades do adolescer ${ }^{(7-8)}$ como implicações a serem consideradas nas estratégias de acolhimento das vítimas e prevenção da violência. Acredita-se que a atual organização dos serviços de saúde não absorve as demandas dessa população e, por vezes, oferece abordagens insuficientes ou centradas exclusivamente nas condições biológicas do desenvolvimento humano. ${ }^{(9)}$

\section{MÉTODO}

Trata-se de um estudo de natureza quantitativa, epidemiológicadescritiva, com delineamento transversal que utilizou dados secundários da base do CEVS alimentada pelas notificações compulsórias de casos suspeitos ou confirmados de violência. O referido banco de dados encontra-se disponível ao público na internet e foi consultado nos meses de maio e junho de 2011, sendo o estudo realizado com uma amostra de 1.896 notificações.

Tendo em vista o interesse pela adolescência, definiu-se a faixa de 10 a 19 anos para compor o estudo em questão, incluindo na análise o período de janeiro de 2009 a dezembro de 2010, os quais representam os anos completos disponíveis nesse banco. As variáveis analisadas estiveram relacionadas às características da vítima (sexo, faixa etária, raça/etnia e escolaridade), do agressor (relação com a vítima) e da agressão/ ocorrência (regional de saúde onde foi notificada e tipo de violência).

Essas informações foram consultadas no programa Tabnet, disponível no site SES/RS, e transportados para uma planilha eletrônica. A análise dos dados utilizou-se da estatística descritiva com expressão das frequências relativas e absolutas, bem como foram calculados os coeficientes de morbidade com base nos dados censitários do IBGE, disponível no DATASUS.

Por serem informações públicas disponíveis para consulta livre online, julga-se desnecessária a submissão do projeto de pesquisa a um Comitê de Ética em Pesquisa, levando em consideração a manutenção do anonimato dos envolvidos e a não especificação do município envolvido. O compromisso com os aspectos éticos consistiram-se na citação da base de dados consultada.

\section{RESULTADOS}

A análise realizada com base nos dados disponíveis nas Informações de Saúde do CEVS permitiu caracterizar os adolescentes gaúchos que foram vítimas de violência nos anos de 2009 e 2010, segundo as notificações realizadas no período. A Tabela 1 apresenta essas características.

Frente ao exposto, é possível constatar que a violência notificada no Rio Grande do Sul tem feito mais vítimas entre adolescentes do sexo feminino, em ambos os anos. Em 2009, a faixa etária de 10 a 14 anos representou $74,2 \%$ das notificações de violência contra adolescentes, enquanto que no ano de 2010 as notificações se assemelharam muito entre as duas faixas etárias, demonstrando aumento das notificações, principalmente entre adolescentes de 15 a 19 anos. 
Tabela 1 - Características sóciodemográficas dos adolescentes vítimas de violência segundo notificações no Rio Grande do Sul, 2009 e 2010.

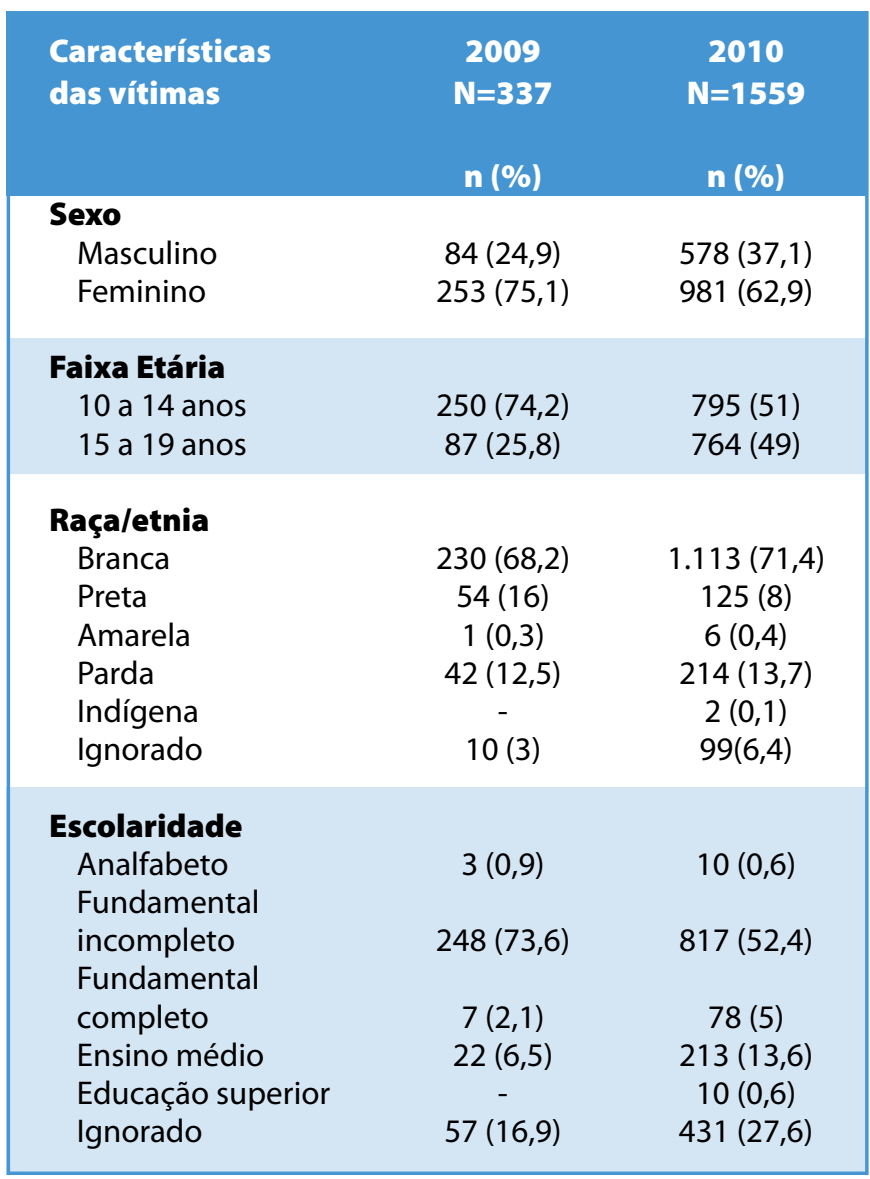

Fonte: Secretaria de Saúde do Estado do Rio Grande do Sul (Tabnet).

Tabela 2 - Distribuição dos tipos de violência notificados contra adolescentes no Rio Grande do Sul, segundo sexo. Rio Grande do Sul. 2009 e 2010.

\begin{tabular}{|c|c|c|c|c|}
\hline \multirow[t]{2}{*}{ Tipos } & \multicolumn{2}{|c|}{2009} & \multicolumn{2}{|c|}{2010} \\
\hline & $F(N=253)$ & $M(N=84)$ & $F(N=981)$ & $M(N=578)$ \\
\hline $\begin{array}{l}\text { Lesão } \\
\text { autoprovocada }\end{array}$ & $9(3,5)$ & - & $92(9,4)$ & $42(7,3)$ \\
\hline Violência física & $82(32,4)$ & $49(58,3)$ & $486(49,5)$ & $404(69,9)$ \\
\hline $\begin{array}{l}\text { Violência } \\
\text { psicológica/moral }\end{array}$ & $105(41,5)$ & $35(41,7)$ & $349(34,6)$ & $126(21,8)$ \\
\hline Violência sexual & $198(78,3)$ & $33(39,3)$ & $405(41,3)$ & $57(9,9)$ \\
\hline $\begin{array}{l}\text { Abandono/ } \\
\text { negligência }\end{array}$ & $22(8,7)$ & $19(22,3)$ & $111(11,3)$ & $66(11,4)$ \\
\hline Ignorados & $59(23,3)$ & $19(22,6)$ & $638(65)$ & $381(66)$ \\
\hline Total $^{1}$ & $475(75,4)$ & $155(24,6)$ & $2081(65,9)$ & $1076(34,1)$ \\
\hline
\end{tabular}

${ }^{1}$ Calculado com base no total de violências notificadas em 2009 ( $N=630$ ) e em 2010 ( $N=3.157$ ), sendo que os tipos de violência não são variáveis excludentes, podendo a mesma vítima ter sofrido mais de um tipo de violência.

Fonte: Secretaria de Saúde do Estado do Rio Grande do Sul.
A análise revela maior prevalência de notificações na raça branca. Ressalta-se, contudo, que no Rio Grande Sul a população negra é muito menor que a branca e, por isso, embora as ocorrências sejam menores, os adolescentes negros são mais acometidos pela violência se levadas em conta essas proporções. O nível de escolaridade mostra que os adolescentes com ensino fundamental incompleto foram os mais atingidos.

A análise da distribuição da notificação da violência, segundo as Coordenadorias Regionais de Saúde, tornou-se limitada no ano de 2009 pela falta de notificações em muitas coordenadorias (13 não tiveram nenhuma notificação e 6 tiveram números muitos baixos de notificação), fato que se justifica por ter sido esse o ano de implantação da proposta no estado. Já em 2010 a situação modificou-se e nenhuma coordenadoria deixou de notificar seus casos de violência, revelando adesão gradativa ao sistema de notificação.

No ano de 2010, apesar de serem maiores as notificações da violência na coordenadoria de Porto Alegre (662 casos), o coeficiente de morbidade apontou que a violência afetou mais adolescentes nas coordenadorias de Caxias do Sul $(291,6 / 100.000)$ e Cruz Alta $(188,1 / 100.000)$, do que em Porto Alegre (116/100.000).

Além da ocorrência, o estudo realizado permitiu diferenciar os tipos de violência mais notificados contra os adolescentes.

Observa-se que as principais notificações de violência contra o sexo feminino em 2009 foram de violência sexual, ao passo que no sexo masculino a violência física foi a mais notificada. No ano de 2010, houve mudança nesse quadro, prevalecendo a notificação da violência física para ambos os sexos, embora a violência sexual permaneça em destaque para o sexo feminino se comparada ao masculino.

Ao analisar o perfil do agente agressor, observou-se que a violência doméstica soma $41 \%$ das violências notificadas contra adolescentes nos anos de 2009 e 2010. Na faixa etária de 10 a 14 anos, o pai, a mãe e o padrasto foram, respectivamente, os principais perpetradores, enquanto que na faixa dos 15 aos 19 anos aumentam as violências originadas pelos parceiros amorosos, nos quais são incluídos cônjuge, ex-cônjuge, namorado(a), e ex-namorado(a). Nas duas faixas etárias, os "outros agressores"tiveram proporções semelhantes, dentre os quais foram considerados: amigo(a), conhecido(a) e cuidador(a).

$\mathrm{Na}$ análise sobre os tipos de violência notificada segundo perfil do perpetrador, foi possível perceber que a violência física foi originada principalmente por agressores sem relações domésticas (18\%), seguida do pai da vítima $(4,8 \%)$, da mãe $(4,6 \%)$ e das relações amorosas $(4,2 \%)$. Segundo a notificação, a violência psicológica também teve essa sequência, enquanto que a violência sexual se originou principalmente de agressores externos ao $\operatorname{lar}(16,8 \%)$, mas teve como segundo maior perpetrador o padrasto $(6,6 \%)$, seguido do pai $(4,6 \%)$.

Dentre as violências praticadas pela mãe, a principal esteve relacionada ao abandono e/ou negligência (6,3\%), 
seguida pela violência psicológica e moral (4,7\%). O principal tipo de violência praticado pelo pai foi a violência psicológica $(5,5 \%)$, seguida pela violência física $(4,8 \%)$.

\section{DISCUSSÃO}

Diante das fragilidades apresentadas pela subnotificação, destaca-se a importância da sensibilização dos profissionais de saúde para a notificação das situações de violência, bem como a necessidade de investimentos na orientação de professores, cuidadores e sociedade para esta causa. Trata-se, portanto, de um desafio relacionado à concepção de justiça que 0 ato de notificar e suas consequências podem trazer. ${ }^{(5)}$ Além disso, salienta-se que por meio das notificações "a violência alcança visibilidade, possibilitando o dimensionamento epidemiológico do problema e a criação de políticas públicas voltadas à sua prevenção". (10:2404)

Dentre as violências notificadas, constatou-se que os adolescentes do sexo feminino foram as principais vítimas, o que se distingue dos resultados de estudo ${ }^{(11)}$ realizado em uma cidade da Bahia. Ainda sobre o sexo das vítimas, destaca-se o achado que as meninas são muito mais acometidas pela violência física do que os meninos, o que corrobora os achados de outro estudo ${ }^{(12)}$ realizado em Ribeirão Preto/SP.

Quanto ao destaque atribuído à violência doméstica, tratase de achado muito semelhante a estudo ${ }^{(11)}$ realizado em Feira de Santana/BA, o qual somou $42,8 \%$ das violências notificadas contra crianças e adolescentes no conselhos tutelares.
Em se tratando dos perpetradores da violência sexual, os resultados se diferem de outro estudo ${ }^{(12)}$, no qual a maioria das vítimas tiveram o pai como principal responsável. Ainda em relação à violência sexual, estudo realizado em Porto Alegre ${ }^{(13)}$, com o objetivo de verificar a prevalência da exposição à violência sexual entre adolescentes estudantes de escolas estaduais, corrobora com os resultados do presente estudo, revelando o sexo feminino com mais vítimas entre os adolescentes.

Quando comparados os dados encontrados no Rio Grande do Sul com o estudo ${ }^{(11)}$ realizado em Feira de Santana e em Montreal, observam-se semelhanças quanto aos perpetradores, pois em ambos os estudos a mãe aparece como principal responsável pela negligência e a madrasta pela violência física. Entretanto, os estudos divergem quanto à violência praticada pelo pai e pelo padrasto à medida que em Feira de Santana e em Montreal o pai pratica mais a negligência e o padrasto mais a violência física.

\section{CONCLUSÃO}

Salienta-se a necessidade de mais estudos sobre a temática, bem como de melhorias nas notificações para que estas possam servir de base para a construção de estratégias de prevenção e promoção da saúde dos adolescentes, uma vez que esse público continua, de certa forma, invisível aos serviços de saúde. Este estudo pode contribuir para despertar os profissionais, a sociedade e os próprios adolescentes para a organização de ações que visualizem o fenômeno da adolescência e da violência como prioridade nas agendas públicas.

\section{Referências}

1. Souza MKB, Santana JSS. Atenção ao adolescente vítima de violência:

participação de gestores municipais de saúde. Ciênc Saúde Coletiva.

2009;14(2):547-55

2. Krug EG, Dahlberg LL, Mercy JÁ, Zwi AB, Lozaro R. World Report on violence

and health. Genebra: World Health Organization; 2002.

3. Ministério da Saúde (BR). Secretaria de Atenção à Saúde. Departamento de Ações

Programáticas Estratégicas. Linha de cuidado para a atenção integral à saúde de

crianças, adolescentes e suas famílias em situação de violências: orientação para

gestores e profissionais de saúde. Brasília: Ministério da Saúde, 2010.

4. Azevedo MA, Guerra VNA. Infância e violência fatal em família. São Paulo: Iglu; 2007

5. Gonçalves HS, Ferreira AL. A notificação da violência intrafamiliar contra

crianças e adolescentes por profissionais de saúde. Cad Saúde Pública.

2002;18(1):315-19,

6. Secretaria Estadual da Saúde (RS). Centro Estadual de Vigilância em Saúde.

Notificação Compulsória de casos suspeitos ou confirmados de violência. Porto

Alegre: CEVS; 2009.

7. UNICEF. O direito de ser adolescente: oportunidade para reduzir

vulnerabilidades e superar desigualdades. Brasília: UNICEF, 2011.
8. Camargo BV, Botelho LJ. Aids, sexualidade e atitudes de adolescentes sobre proteção contra o HIV [Internet]. [citado em 2011 Jun 6]. Disponível em: http:// www.scielo.br/pdf/rsp/v41n1/5296.pdf

9. Ayres JRCM. Práticas educativas e prevenção de HIV/Aids: lições aprendidas e desafios atuais. Interface Comum Saúde Educ. 2002;6(11):11-24.

10. Santos BLL, Silva JL, Silva ICA. Comparação entre indicadores de violência: análise situacional do VIVA 2009 [Internet]. [citado em 2012 Jun 5]. Disponível em: http:// www.ufpe.br/revistaenfermagem/index.php/revista/article/view/1996/pdf_718 11. Costa $M C O$, Bigras $M$, Souza KEP, Carvalho RC, Santos CAST. Violência e abuso contra crianças e adolescentes, segundo os conselhos tutelares, o programa sentinela de Feira de Santana (BA) e o Centre Jeunesse de Montreal. Adolesc Saúde. 2008;5(2).

12. Ribeiro $M A$, Ferriani $M G$, Reis JN. Violência sexual contra crianças e adolescentes: características relativas à vitimização nas relações familiares. Cad Saúde Pública. 2004;20(2):456-64.

13. Polanczyk GV, Zavaschi ML, Benetti $S$, Zenker R, Gammerman PW. Violência sexual e sua prevalência em adolescentes de Porto Alegre, Brasil. Rev Saúde Pública. 2003;37(1):8-14. 